\title{
Chondroitin sulfate proteoglycans inhibit the migration and differentiation of oligodendrocyte precursor cells and its counteractive interaction with laminin
}

\author{
YI SUN ${ }^{1,2}$, YINGPING DENG ${ }^{1}$, MILI XIAO ${ }^{1}$, LAN HU $^{1}$, ZHIHUA LI $^{1}$ and $\mathrm{CHAO} \mathrm{CHEN}^{1,2}$ \\ ${ }^{1}$ Department of Neonatology, Children's Hospital of Fudan University; \\ ${ }^{2}$ Key Laboratory of Neonatal Disease, Ministry of Health, Shanghai 201102, P.R. China
}

Received January 16, 2017; Accepted September 19, 2017

DOI: $10.3892 /$ ijmm.2017.3153

\begin{abstract}
Cerebral white matter injury (WMI) is a recognized problem in premature infants, particularly in those with very low birth weights. Although the survival rate of premature infants has notably increased due to the advancement of modern medical treatments, their likelihood of developmental disability is higher than infants with an average birth weight. It has been previously reported that oligodendrocyte precursor cells (OPCs) are selectively vulnerable to WMI in premature infants. Following brain injury, glial scars may develop within the white matter. Their main constituent is chondroitin sulphate proteoglycans (CSPGs), revealing a potential association between CSPGs and OPCs. In the present study rat OPCs were cultured in vitro, and the effect of CSPGs on the proliferation, migration and differentiation of OPCs was determined. It was revealed that CSPGs did not affect proliferation, but they did inhibit the migration and differentiation of OPCs. It was also identified that the inhibitory effect of CSPGs was counteracted by laminin. Factor analysis revealed that CSPGs and laminin served interactive roles in OPC differentiation. The effect of CSPGs on OPCs was associated with the downregulation of $\beta 1$-integrin, indicating that CSPGs potentially competitively inhibit the $\beta 1$-integrin signaling pathway. Collectively, these results suggest that CSPGs serve a role as inhibitors of OPC differentiation and migration, as well as indicating an interaction between CSPGs and laminin. The present study has revealed a potential novel therapeutic target for WMI in premature infants, and identified $\beta 1$-integrin signaling as a pathological mechanism for dysfunctional myelination in white matter.
\end{abstract}

Correspondence to: Dr Chao Chen, Key Laboratory of Neonatal Disease, Ministry of Health, 399 Wanyuan Road, Shanghai 201102, P.R. China

E-mail: chen6010@163.com

Key words: oligodendrocyte precursor cells, chondroitin sulphate proteoglycans, migration, differentiation, brain injury, $\beta 1$-integrin

\section{Introduction}

Cerebral white matter injury (WMI) is a recognized problem in premature newborns, particularly those with a very low birth weight (VLBW) (1). In 2010, the number of infants with a VLBW is likely to exceed several million worldwide (2). Between 1990 and 1998, >85\% of VLBW infants survived in the USA $(3,4)$. However, their likelihood of long-term neurodevelopmental disability is increased compared with newborns that have an average birth weight (4). Common disabilities exhibited by newborns with a VLBW include spastic motor deficits (5-10\% of survivors) (5) and cognitive socialization defects (25-50\% of survivors) (6). These conditions can significantly impair the patient's quality of life. Therefore, it is of great clinical significance to study the treatment and potential therapeutic targets of WMI in premature infants.

Oligodendrocyte precursor cells (OPCs) are selectively vulnerable to WMI in premature infants (7). The targeted death of OPCs is responsible for acute WMI mediated by lipid peroxidation in preterm infants (8). The pathological mechanisms underlying the death of OPCs are currently unknown; however, specific events have been identified, including upstream hypoxia and inflammation, and downstream microglia activation and cytotoxicity of excitatory amino acids (9). A previous study revealed that surviving OPCs often failed to differentiate, leading to a loss of cellular functions due a decreasing production of compact myelin (10). Myelination is a key process during the maturation of OPCs; it supports neuronal growth, is involved in neural transduction, and serves an important role in recognition and motor function (11). Therefore, the maturation of OPCs is the basis for normal myelination, while impaired migration and differentiation of OPCs hinders myelination.

A previous study has demonstrated that extracellular matrix (ECM) components, particularly chondroitin sulfate proteoglycans (CSPGs), are associated with the regeneration and plasticity of the central nervous system; removal of CSPGs was revealed to facilitate axonal regeneration and functional recovery (12). CSPGs are a mechanical barrier that inhibit the migration, differentiation and recovery of neural cells, and a chemical barrier that secretes inhibitors to prevent the outgrowth of neuronal axons (13). Siebert and Osterhout (14) 
demonstrated that CSPGs inhibit OPC process outgrowth and differentiation, thus indicating a direct association between CSPGs and the differentiation of OPCs. However, the mechanism by which this occurs remains unknown, and the effect of CSPGs on the proliferation and migration of OPCs is unclear. The potential interactions between CSPGs and other components of the ECM, including laminin have not yet been identified.

In the present study, the role of CSPGs in the proliferation, migration and differentiation of OPCs was investigated. The interactive association between CSPGs and laminin in the maturation and differentiation of OPCs was also examined. The inhibitory effect of CSPGs on OPC differentiation was identified to be associated with $\beta 1$-integrin. The present study provides novel insights into the underlying mechanisms of myelination impairment in brain injuries in premature infants. This may provide a basis to identify novel therapeutic targets.

\section{Materials and methods}

OPC culture. A total of 12 male postnatal day 1 Sprague Dawley rats (mean weight, $10 \pm 2 \mathrm{~g}$ ) were obtained from the Experimental Animal Center of Sun Yat-sen University (Guangzhou, China). The rats were housed in an environment with a standard $12 \mathrm{~h}$ light/dark cycle and ad libitum access to food and water. On postnatal day 2, the rats were sacrificed to obtain OPCs, which were cultured as previously described (15). The cerebral cortexes from the rats were cut into sections of $\sim 1 \mathrm{~mm}^{3}$ in size, and then digested in minimal essential media with $1.5 \mathrm{mg} / \mathrm{ml}$ papain and $60 \mu \mathrm{g} / \mathrm{ml}$ DNase I (both from Gibco; Thermo Fisher Scientific, Inc., Waltham, MA, USA). Following centrifugation at $300 \mathrm{x}$ g for $5 \mathrm{~min}$ at $4^{\circ} \mathrm{C}$, the cell suspension was seeded in poly-L-lysine coated $\mathrm{T} 75$ culture flasks and cultured in Dulbecco's modified Eagle's medium (DMEM) supplemented with 20\% fetal bovine serum (both from Gibco; Thermo Fisher Scientific, Inc.). After 10 days, the flasks were placed in an agitator at $37^{\circ} \mathrm{C}$ for $1.5 \mathrm{~h}$ to remove microglia. Following this, an additional agitation was performed for $16 \mathrm{~h}$ at $37^{\circ} \mathrm{C}$ to detach OPCs, which were subsequently seeded onto poly-D-lysine-coated plates and cultured in OPC proliferation medium [OPCM; DMEM/F12 (Gibco; Thermo Fisher Scientific, Inc.) supplemented with 2\% B27 (Invitrogen; Thermo Fisher Scientific, Inc.), $1 \%$ penicillin-streptomycin (Gibco; Thermo Fisher Scientific, Inc.), $20 \mathrm{ng} / \mathrm{ml}$ platelet-derived growth factor (PDGF)-AA and $20 \mathrm{ng} / \mathrm{ml}$ basic fibroblast growth factor (bFGF) (both from Invitrogen; Thermo Fisher Scientific, Inc.)]. The flasks were maintained at $37^{\circ} \mathrm{C}$ and half of the medium was changed every other day. The present study was approved by the Ethics Committee of the Children's Hospital of Fudan University (Shanghai, China).

OPC differentiation. To induce differentiation into mature oligodendrocytes, the OPCs were seeded into a 24-well plate at a concentration of $5 \times 10^{4}$ cells/ml per well. After $24 \mathrm{~h}$ the cells were cultured in oligodendrocyte differentiation medium [OLM; DMEM/F12 supplemented with 2\% B27 (Invitrogen; Thermo Fisher Scientific, Inc.), Triiodo-L-thyronine (T3; $40 \mathrm{ng} / \mathrm{ml}$ ) and L-Thyroxine (T4; $30 \mathrm{ng} / \mathrm{ml}$ ) (both from Sigma-Aldrich; Merck KGaA, Darmstadt, Germany)] for 5 days with the medium changed every day.
Immunocytochemistry. The OPCs were fixed with 4\% paraformaldehyde for $15 \mathrm{~min}$ at room temperature, and subsequently blocked in 2\% bovine serum albumin (BSA; Sigma-Aldrich; Merck $\mathrm{KGaA}$ ) at $37^{\circ} \mathrm{C}$ for $2 \mathrm{~h}$ and $3 \%$ normal goat serum (Beyotime Institute of Biotechnology, Haimen, China) for $1 \mathrm{~h}$. The cells were then incubated with the following primary antibodies overnight at $4^{\circ} \mathrm{C}$ : Rabbit polyclonal anti-PDGF receptor (PDGFR) $\alpha$ (1:40; cat. no. SC-338; Santa Cruz Biotechnology, Inc., Dallas, TX, USA), rabbit polyclonal anti-oligodendrocyte transcription factor (Olig2; 1:200; cat. no. Ab81093; Abcam, Cambridge, UK), mouse monoclonal anti-O4 (1:40; cat. no. O7139; Sigma-Aldrich; Merck KGaA), mouse monoclonal anti-O1 (1:500; cat. no. MAB1327; R\&D Systems, Inc., Minneapolis, MN, USA) and rabbit anti-myelin basic protein (MBP; 1:50; cat. no. Ab53294; Abcam). After incubation with the primary antibodies, the cells were washed twice with $0.1 \%$ Triton X-100 in phosphate-buffered saline (PBS) for $10 \mathrm{~min}$. Following this, the cells were incubated with donkey anti-mouse IgG Alexa Fluor ${ }^{\circledR} 488$ (cat. no. A21202) or donkey anti-mouse IgG Alexa Fluor ${ }^{\circledR} 555$ (cat. no. A31572) secondary antibodies (both 1:200; Molecular Probes; Thermo Fisher Scientific, Inc.) for $1 \mathrm{~h}$ at room temperature. The nuclei were counterstained with 4',6-diamidino-2-phenylindole (DAPI) (1:1,000; cat. no. D1306; Invitrogen; Thermo Fisher Scientific, Inc.) at room temperature for $30 \mathrm{~min}$. The fluorescence images were captured using a fluorescent microscope (magnification, x200) (Olympus Corp., Tokyo, Japan).

Coverslip coating. Coverslips were coated overnight in polyL-ornithine (20 $\mu \mathrm{g} / \mathrm{ml}$; Sigma-Aldrich) and rinsed with sterile deionized $\mathrm{H}_{2} \mathrm{O}$ the following day. The coverslips were subsequently coated overnight in three different concentrations $(1,5$ and $10 \mu \mathrm{g} / \mathrm{ml})$ of laminin (cat. no. L2020; Sigma-Aldrich; Merck KGaA), with CSPGs (cat. no. CC117; EMD Millipore, Billerica, MA, USA) at varying concentrations (1, 2.5, 5 and $10 \mu \mathrm{g} / \mathrm{ml}$ ) or without CSPGs.

MTS assay. Cell proliferation was evaluated by an MTS assay using the CellTiter96 Aqueous Cell Proliferation kit (Promega Corp., Madison, WI, USA), which is a colorimetric method for determining the number of viable cells. This solution contains a tetrazolium compound, MTS, and an electron coupling reagent, phenazine ethosulfate. Following precoating with poly-L-ornithine, the coverslips were coated with laminin $(10 \mu \mathrm{g} / \mathrm{ml})$ in the control group, and laminin and CSPGs $(5 \mu \mathrm{g} / \mathrm{ml})$ in the CSPGs group. Following proliferation, the OPCM was removed at five different time points $(24,48,72$, 96 and $120 \mathrm{~h}$ ) and $20 \mu \mathrm{l}$ MTS reagent with $100 \mu \mathrm{l}$ DMEM was added to each well. Cells were incubated with MTS for $4 \mathrm{~h}$ at $37^{\circ} \mathrm{C}$. The plates were placed in a 96-well microplate reader (FLUOstar Omega; BMG Labtech GmbH, Ortenberg, Germany) and the absorbance was recorded at $490 \mathrm{~nm}$.

EdU analysis. Cell proliferation was also measured by EdU analysis using a Click-iT EdU Detection kit (Thermo Fisher Scientific, Inc.) at $48 \mathrm{~h}$ following proliferation culture. Coverslips were coated with laminin $(10 \mu \mathrm{g} / \mathrm{ml})$ in the control group, and with laminin and low, medium and high $(1,5$ and $10 \mu \mathrm{g} / \mathrm{ml}$, respectively) doses of CSPGs in the CSPGs groups. Briefly, the cells were incubated with EdU for $16 \mathrm{~h}$, 
and subsequently fixed with $4 \%$ paraformaldehyde at room temperature for $15 \mathrm{~min}$. Following fixation, the cells were washed with PBS and 3\% BSA, followed by incubation in PBS with $0.3 \%$ Triton $\mathrm{X}-100$. The Click-iT mix solution was added to the wells and the cells were kept in the dark for $30 \mathrm{~min}$. Following washing with $0.1 \%$ Triton $\mathrm{X}-100$ in PBS twice for $5 \mathrm{~min}$ at room temperature, the nuclei were counterstained with DAPI at room temperature for $5 \mathrm{~min}$. The images were captured using a fluorescent microscope (magnification, x200).

Transwell assay. The migration of the OPCs was measured using a Transwell assay. The Transwell polycarbonate membrane inserts (Corning Inc., Corning, NY, USA) were put into a 24-well plate. Firstly, the effect of CSPGs on OPC migration as a mechanical barrier was investigated. The polycarbonate membrane was coated in either $10 \mu \mathrm{g} / \mathrm{ml}$ laminin or laminin with 1,5 or $10 \mu \mathrm{g} / \mathrm{ml} \mathrm{CSPGs.} \mathrm{The} \mathrm{cells} \mathrm{were} \mathrm{seeded}$ into the upper chamber of the Transwell plate $\left(8 \times 10^{4}\right.$ cells/well $)$ and cultured with $200 \mu \mathrm{lOPCM} /$ well without bFGF and PDGF-AA, whereas the bottom chamber contained $600 \mu \mathrm{l}$ OPCM/well with $20 \mathrm{ng} / \mathrm{ml} \mathrm{bFGF}$ and $20 \mathrm{ng} / \mathrm{ml}$ PDGF-AA to induce cell migration. Cells were allowed to migrate for $4 \mathrm{~h}$, and subsequently stained with $100 \mathrm{ng} / \mathrm{ml}$ DAPI at room temperature for $5 \mathrm{~min}$ following fixation with $70 \%$ ethanol for 30 min. Non-migrated cells were removed with a cotton swab from the upper chamber of the Transwell plate. The fluorescence of cells in the bottom of the Transwell plate was captured using a fluorescent microscope (magnification, x200).

To investigate whether CSPGs functioned as a chemical barrier to inhibit the migration of OPCs, CSPGs $(5 \mu \mathrm{g} / \mathrm{ml})$ and laminin $(10 \mu \mathrm{g} / \mathrm{ml})$ were coated onto the polycarbonate membranes of a Transwell plate (group 1) or added into culture medium in the bottom chamber of a Transwell plate (group 2). In the control group the membrane was only coated with laminin and there were no CSPGs in the culture medium. The migration ratio of the CSPGs group was based on the percentage of control group migration, which was set as $100 \%$.

Morphological assay. Oligodendrocytes that were immunostained with mouse monoclonal anti-O1 antibodies were divided into four types on the basis of their morphology: Type I, primary processes shorter than one cell body in length; type II, primary processes longer than one cell body in length; type III, multiple processes with secondary branching; and type IV, complex branching (tertiary or more) and membranous processes. The cells were counted using Image J software (version 1.48; National Institutes of Health, Bethesda, MD, USA).

Western blot analysis. For protein extraction, the cells were lysed in cell lysis buffer $(140 \mathrm{mM} \mathrm{NaCl}, 10 \mathrm{mM}$ Tris- $\mathrm{HCl}$, $1 \%$ Triton X-100, $1 \mathrm{mM}$ ECTA and $1 \mathrm{X}$ protease inhibitor cocktail). The protein concentration was determined using the Bradford reagent method. A total of $25 \mu \mathrm{g}$ protein was loaded into each lane of a $10 \%$ sodium dodecyl sulfate-polyacrylamide gel electrophoresis (SDS-PAGE) gel, and subsequently blotted onto a polyvinylidene difluoride membrane. Following blocking with PBS with Tween-20 containing 5\% nonfat dry milk at room temperature for $1 \mathrm{~h}$, the membrane was incubated with primary antibodies directed against $\beta 1$-integrin (1:200; cat. no. AB1952; EMD Millipore) and glyceraldehyde 3-phos- phate dehydrogenase (GAPDH) (1:5,000; cat. no. 2118; Cell Signaling Technology, Inc., Danvers, MA, USA) overnight at $4^{\circ} \mathrm{C}$. The membrane was then incubated with peroxidaselinked immunoglobulin $\mathrm{G}$ secondary antibodies (Thermo Fisher Scientific, Inc.). The proteins were visualized using an Enhanced Chemiluminescence Western Blotting Detection kit (GE Healthcare, Chicago, IL, USA) according to the manufacturer's protocol. The western blot analysis results were quantified using ImageJ software (the National Institutes of Health).

Reverse transcription-quantitative polymerase chain reaction (RT-qPCR) analysis. RT-qPCR was performed to detect the expression of $\beta 1$-integrin mRNA. Total RNA extraction was performed using a TRIzol reagent (Thermo Fisher Scientific, Inc.) according to the manufacturer's protocol. A total of $2 \mu \mathrm{g}$ of total RNA extracted from the OPCs was subjected to RT. Synthesis of cDNA was performed using the One-Step RT-PCR kit (Takara Bio, Inc., Otsu, Japan) according to the manufacturer's protocol. SYBR-Green (Toyobo Life Science, Osaka, Japan) RT-qPCR amplification and real-time fluorescence detection were performed using an ABI 7300 Real-Time PCR system (Thermo Fisher Scientific, Inc.) according to the manufacturer's protocol. The thermocycling conditions were as follows: $95^{\circ} \mathrm{C}$ for $30 \mathrm{sec}$; 40 cycles of $95^{\circ} \mathrm{C}$ for $15 \mathrm{sec}, 60^{\circ} \mathrm{C}$ for $30 \mathrm{sec}$ and $72^{\circ} \mathrm{C}$ for $45 \mathrm{sec}$; and $72^{\circ} \mathrm{C}$ for $10 \mathrm{~min}$. Relative gene expression was calculated using the $2^{-\Delta \Delta \mathrm{Cq}}$ method (16). The primers used for $\beta 1$-integrin were as follows: Forward, 5'-GAGAACCACAGAA GTTTACA-3' and reverse, 5'-CTGAAGTAATCCTCCTCATT TCA-3'. The relative expression levels were normalized to expression of endogenous GAPDH. The primers used for GAPDH were: Forward, 5'-GCAAGAGAGAGGCCCTCAG-3' and reverse, 5'- TGTGAGGGAGATGCTCAGTG-3'.

Statistical analysis. Raw data were analyzed using SPSS version 20.0 software (IBM Corp., Armonk, NY, USA) and presented as the mean \pm standard deviation. The statistical significance of differences between two groups was determined by one-way analysis of variance followed by a post hoc Fisher's least significant difference test was used for the comparisons of multiple groups. The interactive role between laminin and CSPGs was determined by factor analysis. $\mathrm{P}<0.05$ was considered to indicate a statistically significant difference.

\section{Results}

Characterization of OPCs. Following isolation and purification, OPCs were oval in shape and demonstrated a typical bipolar morphology (Fig. 1A). Similar morphology was observed through immunostaining for OPC biomarkers, including PDGFR $\alpha$ (Fig. 1B), Olig2 (Fig. 1C) and O4 (Fig. 1D). Statistically, $97.3 \pm 1.22 \%$ of the cells were immunoreactive to O4, which indicates the high purity of the cultured OPCs (Fig. 2). Subsequently, the differentiation capacity of the OPCs was determined. Following treatment with OLM, the OPCs differentiated into mature oligodendrocytes with a spider web-like morphology (Fig. 3). Immunocytochemistry data demonstrated that these differentiated cells expressed the mature oligodendrocyte markers O1 (Fig. 3A) and MBP (Fig. 3B). Collectively, these results indicate that cultured OPCs possess the capacity to generate mature oligodendrocytes. 

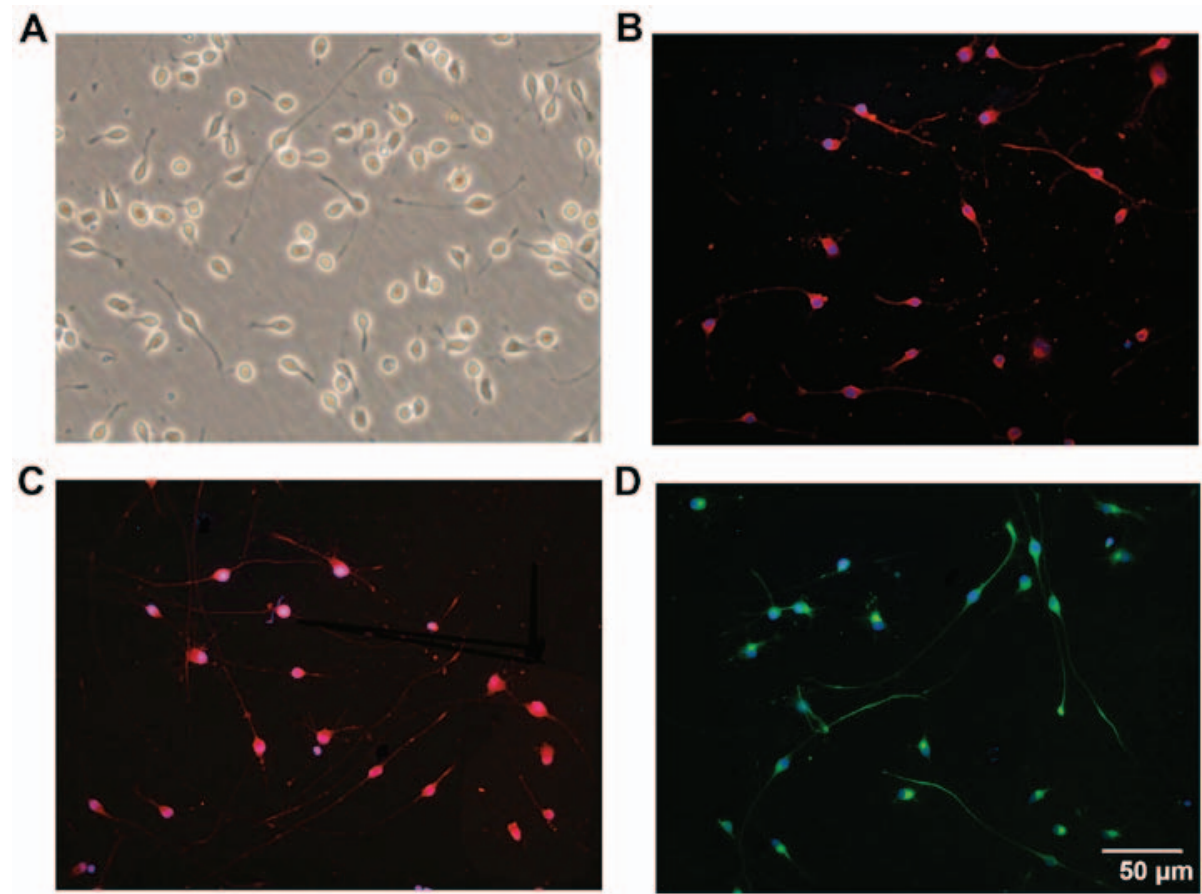

Figure 1. Immunostaining characterization of OPCs cultured in vitro. (A) The typical morphological features of OPCs under bright fields are represented. The cells were identified to express the OPC biomarkers (B) platelet-derived growth factor receptor- $\alpha$, (C) oligodendrocyte transcription factor and (D) O4. Nuclei were counterstained with DAPI. Scale bar, $50 \mu \mathrm{m}$. OPC, oligodendrocyte precursor cell; DAPI, 4',6-diamidino-2-phenylindole.

A

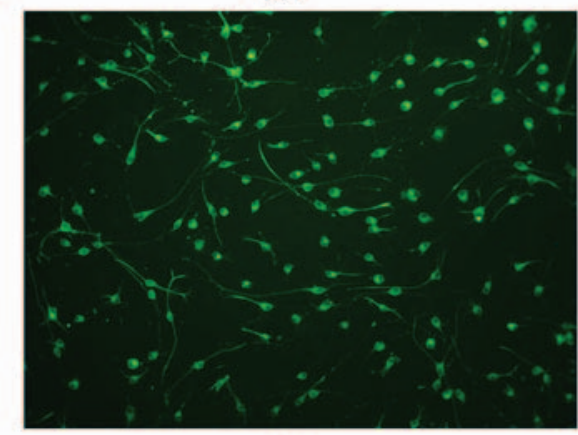

B

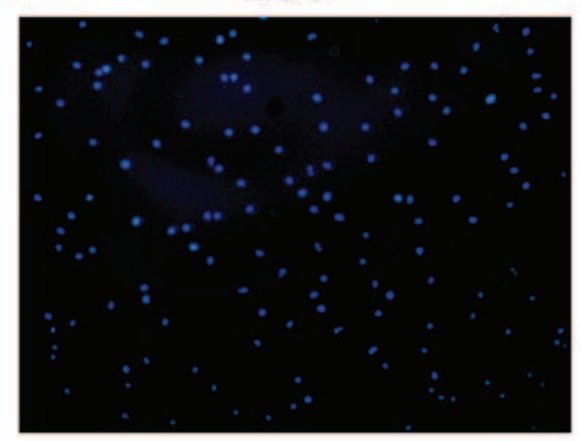

C Merged

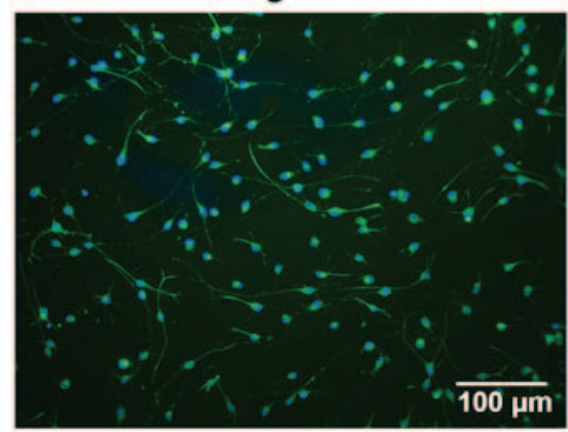

Figure 2. Identification of purified OPCs. (A) The cells exhibited positive immunostaining for O4. (B) The nuclei were counterstained with DAPI and (C) the two images were merged. Statistical analysis indicated the ratio of positively stained cells was $>95 \%$, demonstrating the purity of the cultured OPCs. Scale bar, $100 \mu \mathrm{m}$. OPC, oligodendrocyte precursor cell; DAPI, 4',6-diamidino-2-phenylindole.

CSPGs do not affect the proliferation of OPCs. To determine whether the presence of CSPGs affected the proliferation of OPCs, an EdU analysis and MTS assay were performed (Fig. 4). No significant differences (data not shown) were identified between the control group (Fig. 4A-C) and the CSPGs group (Fig. 4D-F) using EdU analysis. Statistical analysis demonstrated that the ratio of proliferative cells was $68.9 \pm 5.59 \%$ in the control group, whereas the ratios in the low, medium and high dose groups of CSPGs were $63.8 \pm 4.88$, $60.7 \pm 10.41$ and $62.4 \pm 7.24 \%$, respectively (data not shown). 
A

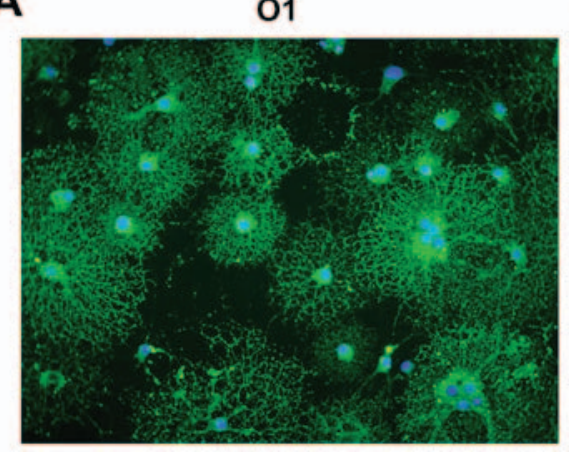

B

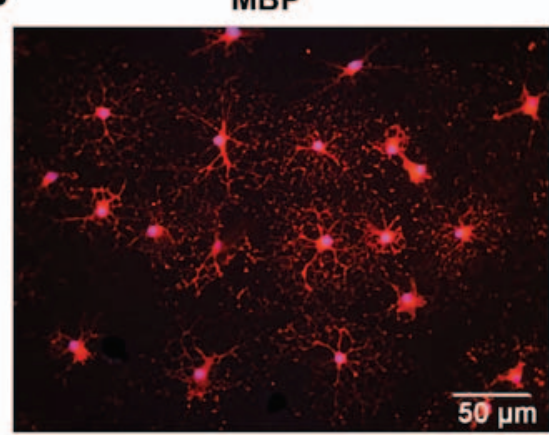

Figure 3. Cultured OPCs possess the capacity to differentiate into mature oligodendrocytes. The differentiated cells express the mature oligodendrocyte biomarkers (A) O1 and (B) MBP when cultured in oligodendrocyte differentiation medium. Scale bar, $50 \mu \mathrm{m}$. OPC, oligodendrocyte precursor cell; MBP, myelin basic protein.

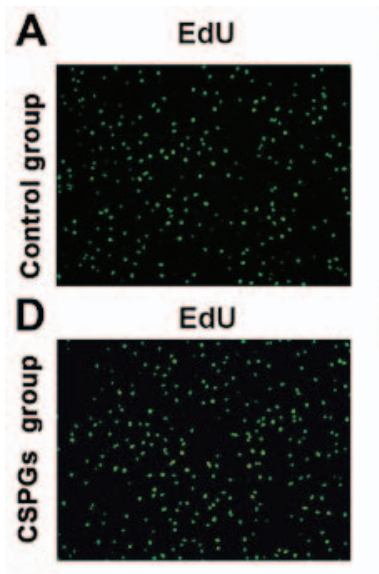

B

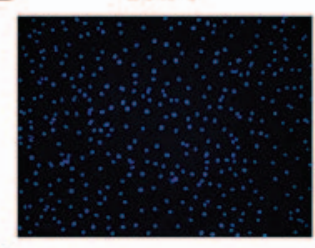

E

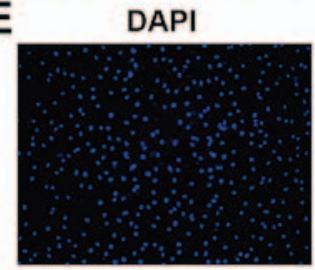

C Merged

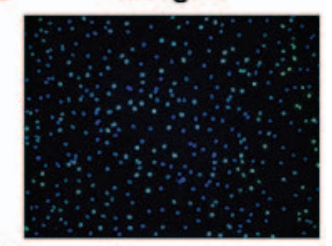

F

Merged

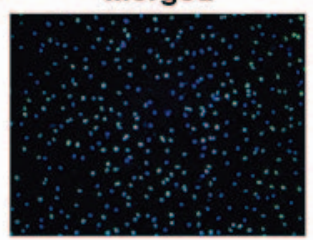

G

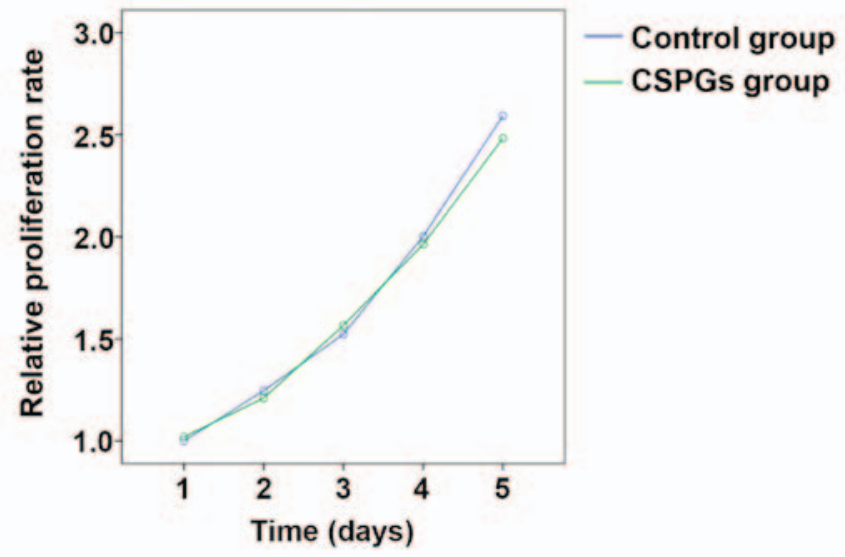

Figure 4. CSPG treatment does not affect the proliferation of cultured OPCs. The ratio of EdU positive cells demonstrated that there was no significant difference between the control group [(A) EdU, (B) DAPI and (C) merged] and the CSPG-treated group [(D) EdU, (E) DAPI and (F) merged]. Scale bar, $100 \mu \mathrm{m}$. (G) No significant differences were identified between the control group and the CSPG group by the MTS assay from day 1 to 5. CSPG, chondroitin sulfate proteoglycan; OPC, oligodendrocyte precursor cell; DAPI, 4',6-diamidino-2-phenylindole.

Similar results were obtained with the MTS assay (Fig. 4G). No significant difference was identified between the control and the CSPG group at five different time points following the treatment of OPCs with CSPGs. These results suggest that CSPG treatment does not alter the proliferation pattern of cultured OPCs in vitro.

CSPGs significantly reduce the migration of OPCs. It was investigated whether treatment with CSPGs changed the migration of OPCs in vitro. The Transwell assay revealed that the migration of OPCs was impaired in a dose-dependent manner with increasing concentrations of CSPGs (Fig. 5). The migration ratio was significantly decreased compared with the control group at all concentrations of CSPGs investigated $(\mathrm{P}<0.01)$. The migration ratio was $68.9 \pm 3.1 \%$ in the presence of $1 \mu \mathrm{g} / \mathrm{ml} \mathrm{CSPGs,} 43.0 \pm 4.3 \%$ with $5 \mu \mathrm{g} / \mathrm{ml} \mathrm{CSPGs}$ ( $\mathrm{P}<0.01$ vs. the control group), and $15.0 \pm 1.5 \%$ with $10 \mu \mathrm{g} / \mathrm{ml}$ CSPGs ( $\mathrm{P}<0.01$ vs. the control group). 

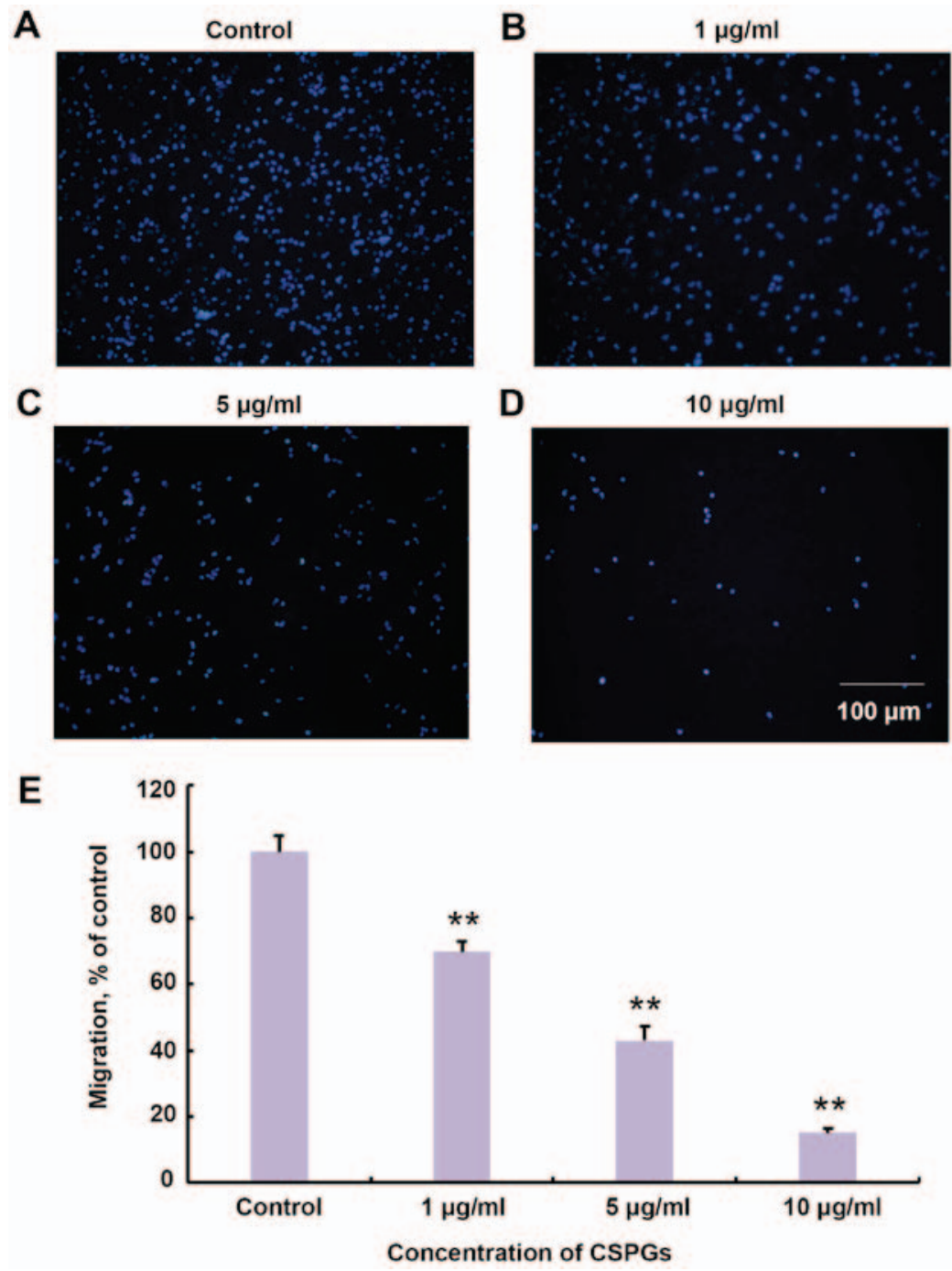

Figure 5. CSPGs act as a mechanical barrier to inhibit the migration of OPCs. When the (A) control group was compared with the (B) 1 , (C) 5 and (D) $10 \mu \mathrm{g} / \mathrm{ml}$ CSPG groups, a clear inhibitory effect of CSPG treatment was visible. This inhibitory effect increased as the concentration of the CSPGs increased. The nuclei were stained with DAPI. Scale bar, $100 \mu \mathrm{m}$. (E) Statistical analysis revealed that the presence of CSPGs significantly decreased the migration of OPCs. ${ }^{* * *} \mathrm{P}<0.01$ vs. the control group. CSPG, chondroitin sulfate proteoglycan; OPC, oligodendrocyte precursor cell; DAPI, 4',6-diamidino-2-phenylindole.

It was subsequently investigated whether a different pattern of CSPGs would affect the migration of OPCs. CSPGs were added to the membrane of the Transwell plate in group 1 (Fig. 6A) and in the culture medium of the bottom chamber in group 2 (Fig. 6B). The number of migrated cells in the two groups was significantly lower than the control group (Fig. 6C and D). The ratio of migrated cells in groups 1 and 2 decreased to $45.1 \pm 2.8$ and $41.3 \pm 2.6 \%$ of the control group, respectively ( $\mathrm{F}=414.517$; $\mathrm{P}<0.01)$ (Fig. 6D). Collectively, these results indicate that CSPGs possess the capacity to inhibit the migration of OPCs as either a mechanical or chemical barrier.

CSPGs inhibit the maturation of OPCs. It was investigated whether CSPGs alter the maturation of OPCs. It was observed that $6 \mathrm{~h}$ following the culturing of OPCs in OPCM, untreated cells (Fig. 7A) had longer processes compared with the CSPG-treated cells (Fig. 7B). This inhibitory effect was ameliorated at $24 \mathrm{~h}$ following culture in OPCM (data not shown). To induce the differentiation of OPCs, OPCM was replaced with OLM. It was revealed that untreated cells expressed O1 (Fig. 7C) and MBP (Fig. 7D), and exhibited the morphology of a complex network, indicating the complete maturation of the oligodendrocytes. By contrast, the CSPG-treated cells had shorter, sparse processes and more suspended cells were observed (Fig. 7E-H). However, the expression of MBP (Fig. 7E) and O1 (Fig. 7G) was still observed in the CSPG-treated cells, indicating that the effect CSPGs had on OPCs maturation was not due to the arrest of cell development at the preoligodendrocyte stage.

Laminin has a counteractive effect on CSPGs and the differentiation of OPCs. It was investigated whether laminin has a counteractive effect on the differentiation of OPCs treated with CSPGs. Coverslips were coated with three different concentrations of laminin $(1,5$ and $10 \mu \mathrm{g} / \mathrm{ml})$, and CSPGs at two different concentrations ( 2.5 and $5 \mu \mathrm{g} / \mathrm{ml}$ ) or without CSPGs. As revealed in Table I, when compared with the cells treated with $10 \mu \mathrm{g} / \mathrm{ml}$ of laminin without CSPGs, the lower doses (5 and $1 \mu \mathrm{g} / \mathrm{ml}$ ) of laminin-treated cells demonstrated the differentiation into all four types of oligodendrocytes. Morphologically, more spider web-like cells with more complex and longer processes were observed in the presence of laminin; this effect increased with 

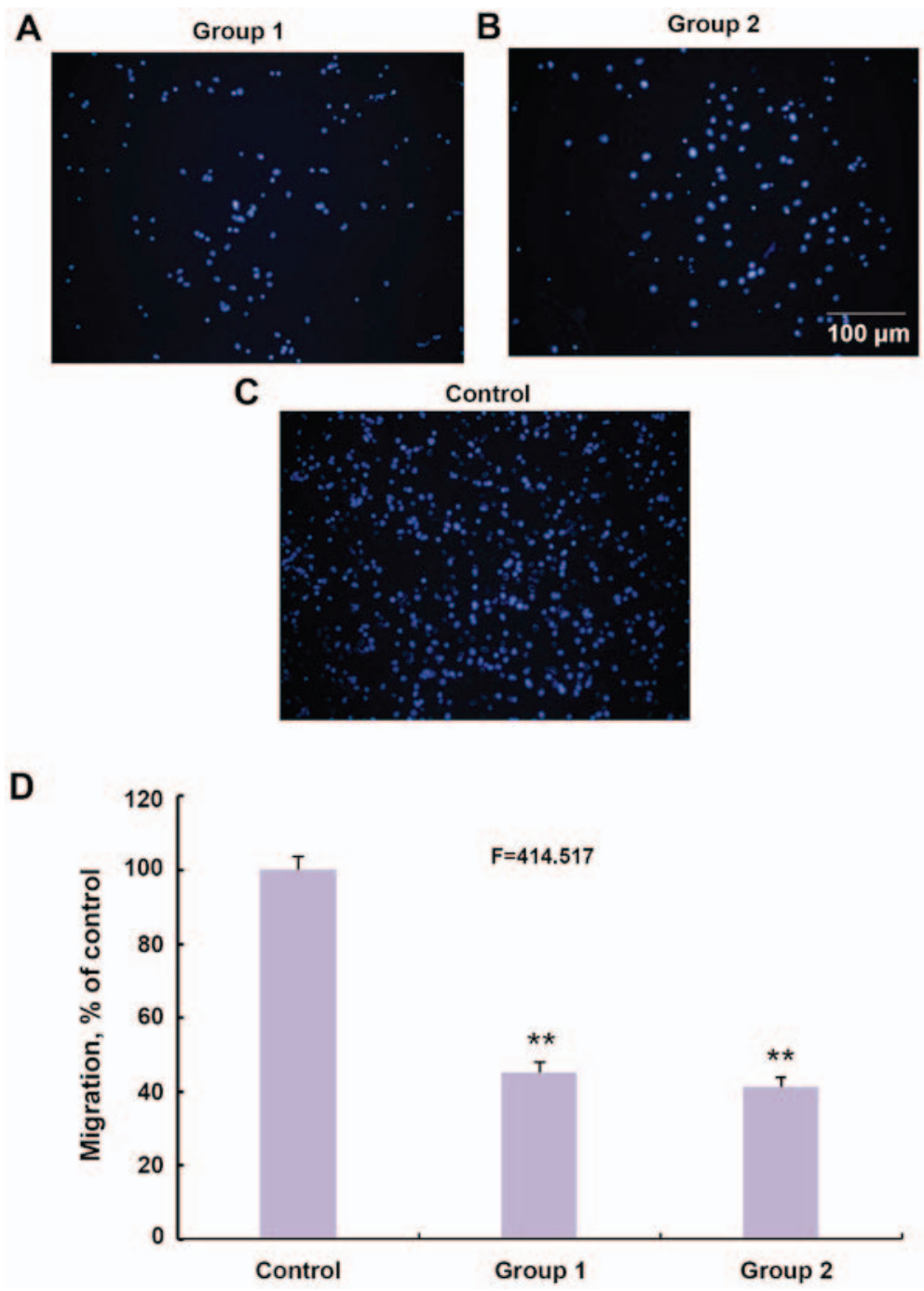

Figure 6. Inhibitory effects of CSPGs on OPCs migration through different types of administration. (A) CSPGs were added onto a Transwell plate membrane or (B) in the culture medium in the bottom chamber of a Transwell plate, and compared with (C) the control group. Scale bar, $100 \mu \mathrm{m}$. (D) Statistical analysis of the captured images revealed a significant reduction in the migration of OPCs in groups 1 and $2 .{ }^{* *} \mathrm{P}<0.01$ vs. the control group. CSPG, chondroitin sulfate proteoglycan; OPC, oligodendrocyte precursor cell.

the higher doses of laminin (Fig. 8A-C) and was observed most prominently with $10 \mu \mathrm{g} / \mathrm{ml}$ laminin. With the co-application of CSPGs and laminin the process outgrowth of OPCs was inhibited (Fig. 8D-F); the higher doses of CSPGs had more prominent inhibitory effects on oligodendrocyte process outgrowth (Fig. 8G-I). However, the cells treated with $1 \mu \mathrm{g} / \mathrm{ml}$ laminin and $2.5 \mu \mathrm{g} / \mathrm{ml}$ CSPGs did not follow this pattern; type II and IV cells increased, whilst type I and III cells decreased (Table I and Fig. 9). Furthermore, an increase in laminin concentration had the opposite effect as an increase in CSPGs, instead resulting in an increase in the ratio of type III and IV cells, and a decrease in the ratio of type I and II cells. These results indicate that laminin treatment facilitates the process outgrowth of oligodendrocytes on CSPGs, as more type IV cells are present. This further contributes to the hypothesis that laminin reduces the impairment of maturation of oligodendrocytes derived from OPCs by CSPGs. The interactive role of laminin and CSPGs was analyzed based on different cell subtypes (Fig. 10 and Table II). The data indicated that different concentrations of CSPGs and laminin affected the differentiation into each of the four cell subtypes differently. These results indicate that laminin has a counteractive effect on CSPGs.

Inhibition of OPC maturation by CSPGs is associated with $\beta 1$-integrin. At 3 and 5 days following OPCs differentiation, the expression level of $\beta 1$-integrin was determined (Fig. 11). At 3 days following differentiation, the protein expression of $\beta 1$-integrin was decreased from $0.98 \pm 0.09$ to $0.82 \pm 0.09$ $(\mathrm{P}<0.05)$ and $0.70 \pm 0.05(\mathrm{P}<0.01)$ when treated with 2.5 and $5 \mu \mathrm{g} / \mathrm{ml}$ CSPGs, respectively (Fig. 11A and B). Similarly, the protein expression of $\beta 1$-integrin was reduced from $0.89 \pm 0.06$ to $0.66 \pm 0.06(\mathrm{P}<0.01)$ and $0.51 \pm 0.04(\mathrm{P}<0.01)$ in the presence of 2.5 and $5 \mu \mathrm{g} / \mathrm{ml}$ CSPGs at 5 days following differentiation (Fig. 11A and B). The $\beta 1$-integrin mRNA level was decreased from $1.02 \pm 0.07$ to $0.78 \pm 0.04(\mathrm{P}<0.01)$ and $0.67 \pm 0.03(\mathrm{P}<0.01)$ when treated with 2.5 and $5 \mu \mathrm{g} / \mathrm{ml}$ CSPGs, respectively, at 3 days following differentiation, and reduced from $0.91 \pm 0.03$ to $0.70 \pm 0.08(\mathrm{P}<0.01)$ and $0.55 \pm 0.07(\mathrm{P}<0.01)$ at 5 days following differentiation (Fig. 11C). The levels of $\beta 1$-integrin protein and mRNA were consistently decreased with increasing treatment with CSPGs, demonstrating that the 
Table I. Composition of the subtypes of oligodendrocytes in the presence of different concentrations of CSPGs and LN.

\begin{tabular}{lccccc}
\hline & & \multicolumn{4}{c}{ Subtype of oligodendrocyte } \\
\cline { 3 - 6 } CSPGs $(\mu \mathrm{g} / \mathrm{ml})$ & $\mathrm{LN}(\mu \mathrm{g} / \mathrm{ml})$ & $\mathrm{I}$ & $\mathrm{II}$ & III & IV \\
\hline 0 & 10 & $1.00 \pm 1.00$ & $3.67 \pm 1.15$ & $11.00 \pm 4.58$ & $84.33 \pm 4.04$ \\
& 5 & $5.33 \pm 1.15^{\mathrm{a}}$ & $7.67 \pm 1.15$ & $17.67 \pm 2.52^{\mathrm{b}}$ & $69.33 \pm 3.79^{\mathrm{b}}$ \\
& 1 & $9.00 \pm 2.00^{\mathrm{b}}$ & $16.7 \pm 2.08^{\mathrm{b}}$ & $37.00 \pm 1.00^{\mathrm{b}}$ & $37.33 \pm 3.06^{\mathrm{b}}$ \\
& 10 & $9.67 \pm 2.52^{\mathrm{b}}$ & $15.33 \pm 1.53^{\mathrm{b}}$ & $35.00 \pm 4.00^{\mathrm{b}}$ & $40.00 \pm 4.36^{\mathrm{b}}$ \\
& 5 & $8.67 \pm 2.52^{\mathrm{b}}$ & $34.00 \pm 5.29^{\mathrm{b}}$ & $26.67 \pm 2.08^{\mathrm{b}}$ & $30.67 \pm 4.04^{\mathrm{b}}$ \\
& 1 & $8.33 \pm 1.52^{\mathrm{b}}$ & $51.67 \pm 2.08^{\mathrm{b}}$ & $25.00 \pm 3.00^{\mathrm{b}}$ & $15.00 \pm 1.00^{\mathrm{b}}$ \\
& 10 & $8.33 \pm 1.52^{\mathrm{b}}$ & $47.00 \pm 4.00^{\mathrm{b}}$ & $28.67 \pm 2.31^{\mathrm{b}}$ & $16.00 \pm 3.60^{\mathrm{b}}$ \\
& 5 & $20.33 \pm 2.52^{\mathrm{b}}$ & $53.00 \pm 2.64^{\mathrm{b}}$ & $20.33 \pm 2.08^{\mathrm{b}}$ & $6.33 \pm 1.53^{\mathrm{b}}$ \\
& 1 & $41.33 \pm 3.60^{\mathrm{b}}$ & $53.66 \pm 4.72^{\mathrm{b}}$ & $4.33 \pm 1.53^{\mathrm{b}}$ & $1.00 \pm 1.00^{\mathrm{b}}$
\end{tabular}

${ }^{\mathrm{a}} \mathrm{P}<0.05$ and ${ }^{\mathrm{b}} \mathrm{P}<0.01$ vs. the control group $(0 \mu \mathrm{g} / \mathrm{ml}$ CSPGs and $10 \mu \mathrm{g} / \mathrm{ml}$ laminin). LN, laminin; CSPGs, chondroitin sulfate proteoglycan.

A

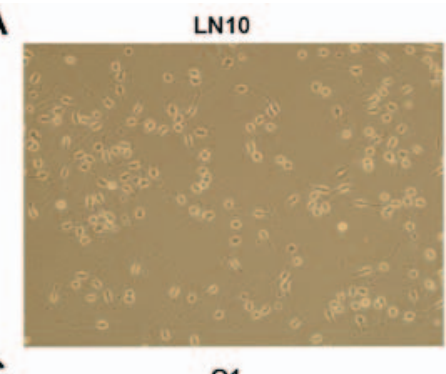

C

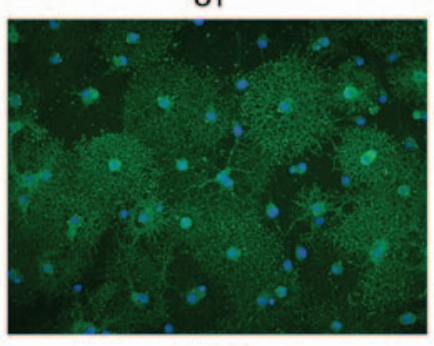

E

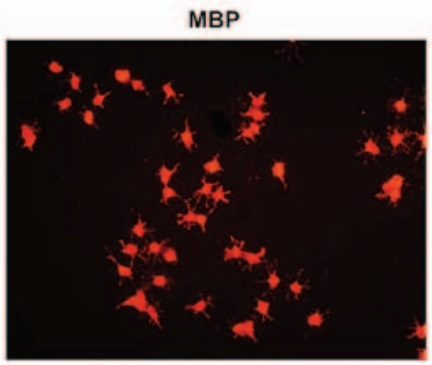

G

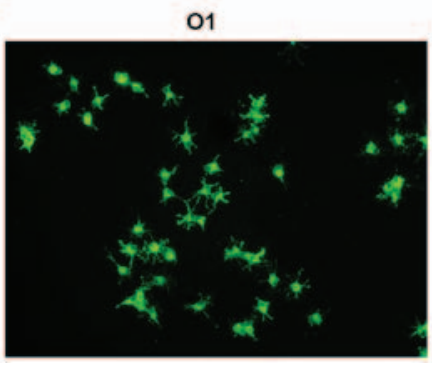

B

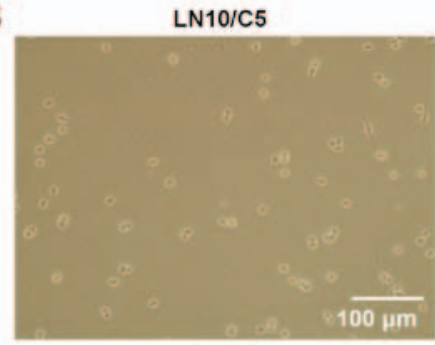

D

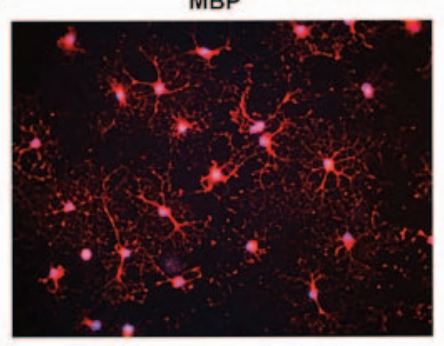

$\mathbf{F}$

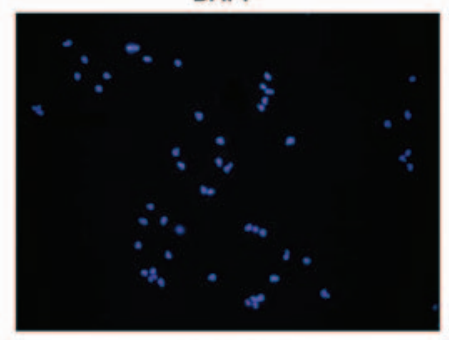

H

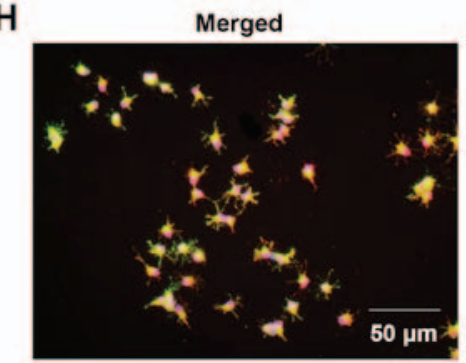

Figure 7. CSPGs inhibit the outgrowth of processes in oligodendrocytes differentiated from OPC cultures. The processes in (A) untreated cells were longer than those in (B) CSPG-treated cells $6 \mathrm{~h}$ following culture in OPC proliferation medium. Scale bar, $100 \mu \mathrm{m}$. The untreated cells expressed (C) O1 and (D) MBP, with mature processes at 5 days following differentiation. The CSPG-treated cells had shorter processes, but still expressed (E) MBP, (F) DAPI and (G) O1. (H) Merged images. Scale bar, $50 \mu \mathrm{m}$. CSPG, chondroitin sulfate proteoglycan; OPC, oligodendrocyte precursor cell; MBP, myelin basic protein; DAPI, 4',6-diamidino-2-phenylindole. 

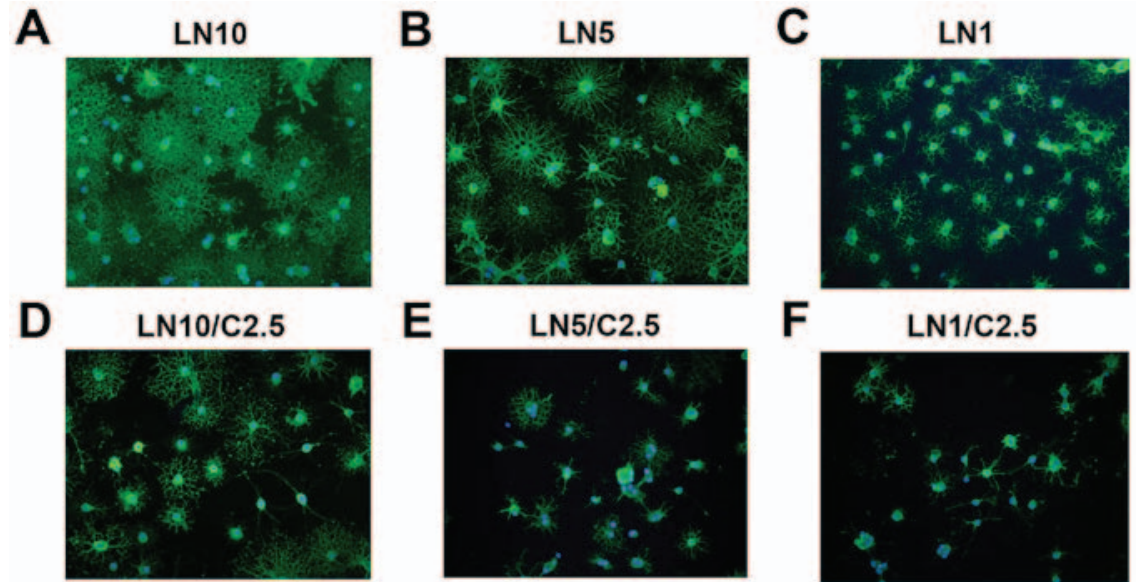

E

LN5/C2.5

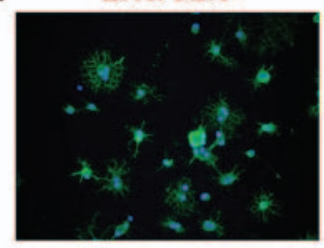

$\mathbf{F}$

LN1/C2.5
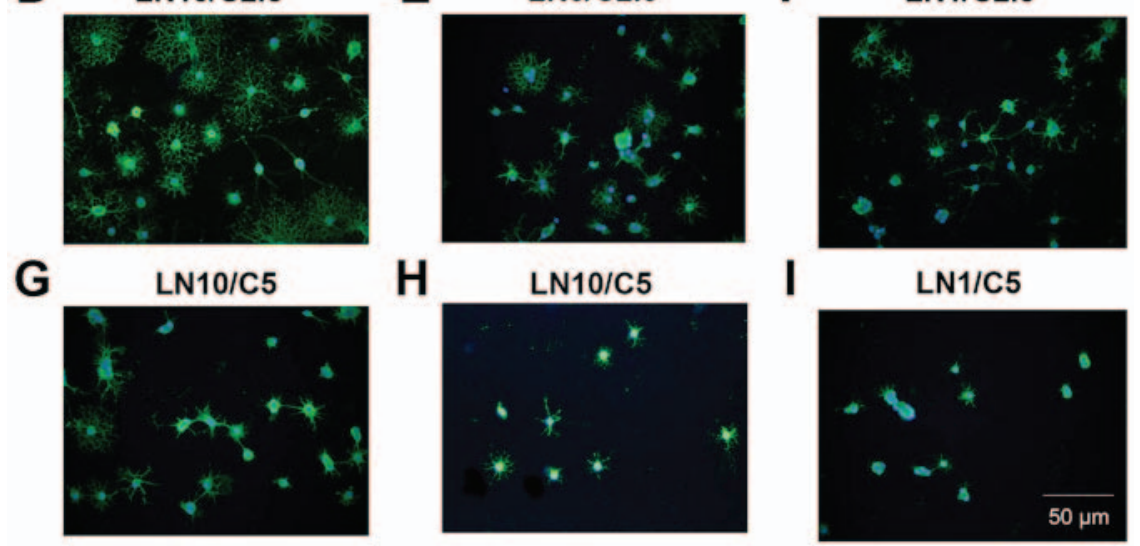

I

LN1/C5

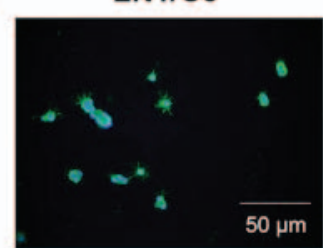

Figure 8. LN offsets C-induced inhibition of oligodendrocytes process outgrowth. LN facilitated the maturation of oligodendrocytes in a dose-dependent manner when administered at (A) 10, (B) 5 and (C) $1 \mu \mathrm{g} / \mathrm{ml}$. LN counteracted the impairment in process outgrowth of oligodendrocytes induced by $2.5 \mu \mathrm{g} / \mathrm{ml} \mathrm{Cs}$ when provided at varying doses: (D) 10, (E) 5 and (F) $1 \mu \mathrm{g} / \mathrm{ml}$. More severe inhibition of process outgrowth was observed in the presence of $5 \mu \mathrm{g} / \mathrm{ml}$ Cs, however, LN was still observed to exhibit a dose dependent effect: (G) 10, (H) 5, (I) $1 \mu \mathrm{g} / \mathrm{ml}$. Scale bar, $50 \mu \mathrm{m}$. C, chondroitin sulfate proteoglycan; LN, laminin.

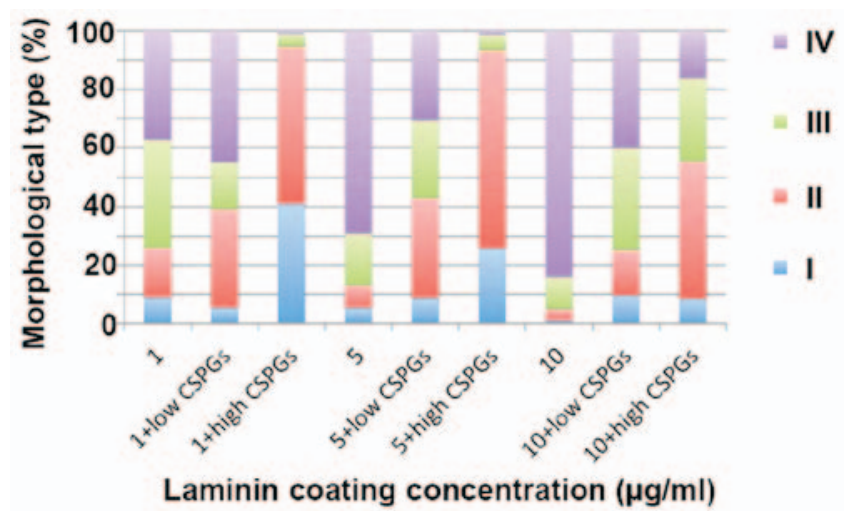

Figure 9. Treatment with laminin and CSPGs affects the differentiation OPCs. The ratio of the four types of oligodendrocytes changed when the OPCs were treated with different concentrations of laminin and CSPGs. Low CSPGs, $2.5 \mu \mathrm{g} / \mathrm{ml}$; high CSPGs, $5 \mu \mathrm{g} / \mathrm{ml}$. CSPG, chondroitin sulfate proteoglycan; OPC, oligodendrocyte precursor cell.

inhibitory effect of CSPGs may be associated with the alteration of $\beta 1$-integrin expression.

\section{Discussion}

WMI is the most common cause of brain injury in preterm infants (17). OPCs are selectively vulnerable to WMI in premature infants (18). CSPGs act as a mechanical barrier to inhibit the migration, differentiation and recovery of neural cells (19). However, the mechanism underlying the correlation between CSPGs and the differentiation, migration and differentiation of OPCs remains unclear. In the present study, the role of CSPGs in inhibiting the migration and differentiation of OPCs was examined. This effect was counteracted by the presence of laminin, revealing the interaction between CSPGs and laminin in the maturation of OPCs. The involvement of $\beta 1$-integrin signaling in the CSPG-induced inhibition of the differentiation of OPCs was also investigated. The results identified a novel mechanism of WMI in premature infants and may provide a novel candidate as a potential therapeutic target.

There are currently 18 identified subtypes of integrin; oligodendrocytes express several different types of integrin and the expression of these receptors is developmentally regulated (20). The interaction between laminin-2 and the integrin that is expressed on an oligodendrocyte is an important part of the formation of the myelin membrane, which is required to cover the axon and form the myelin sheath (21). The present study demonstrated that laminin could potentially offset the inhibitory effect CSPGs have on myelination in oligodendrocytes. Among all the integrin subtypes expressed in oligodendrocytes, $\alpha 6 \beta 1$ is the only known laminin-2 receptor, serving a critical role in the myelination of oligodendrocytes (20). The intracellular proteins correlated with $\beta 1$-integrin include integrin-linked protein kinase, focal adhesion kinase, protein kinase B, tyrosine-protein kinase Fyn, ras-related $\mathrm{C} 3$ botulinum toxin substrate 1 (Rac1), cell division control protein 42 homolog (cdc42) and Rho factor. These proteins are involved in the reconstruction of the cytoskeleton and are therefore important in regulating the morphological development of oligodendrocytes (22). Taking into consideration that OPCs are the progenitors of oligodendrocytes and mainly express $\beta 1$-integrin, which is of great significance in the differentiation of OPCs, it was hypothesized that the $\beta 1$-integrin signaling pathway was the main pathway that regulates the effect of laminin and CSPGs on the differentiation of OPCs. This hypothesis was supported by the results 
A

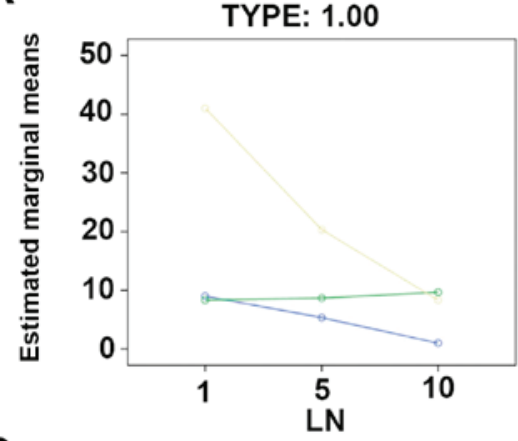

C

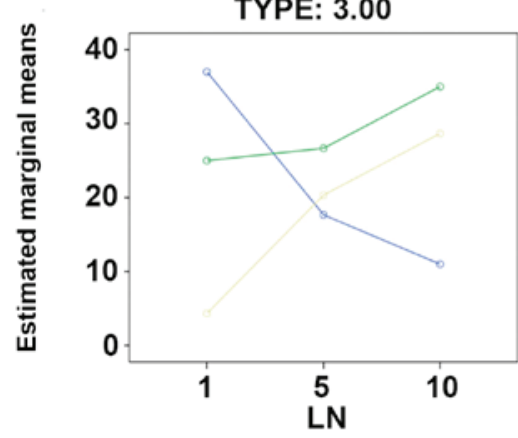

E

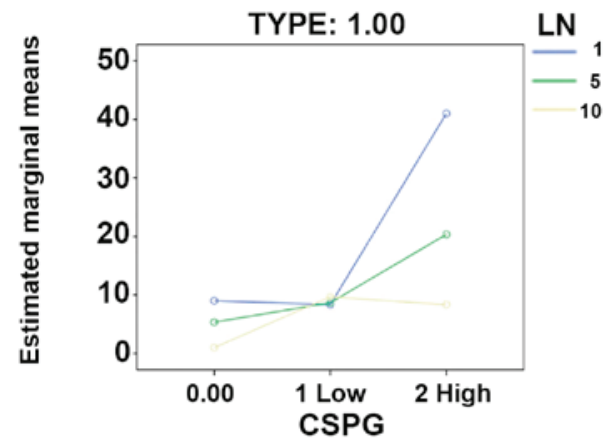

G

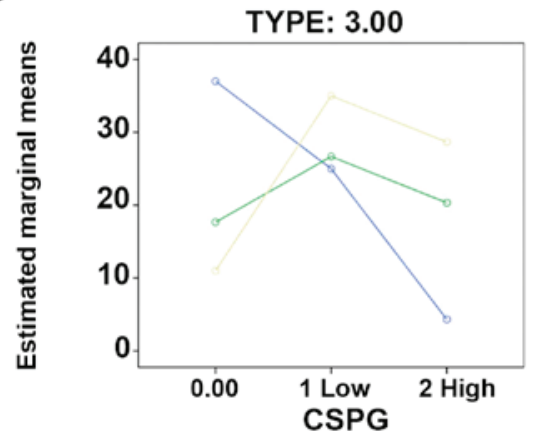

B

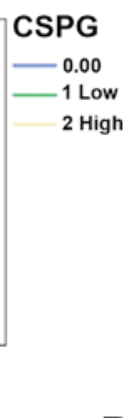

D
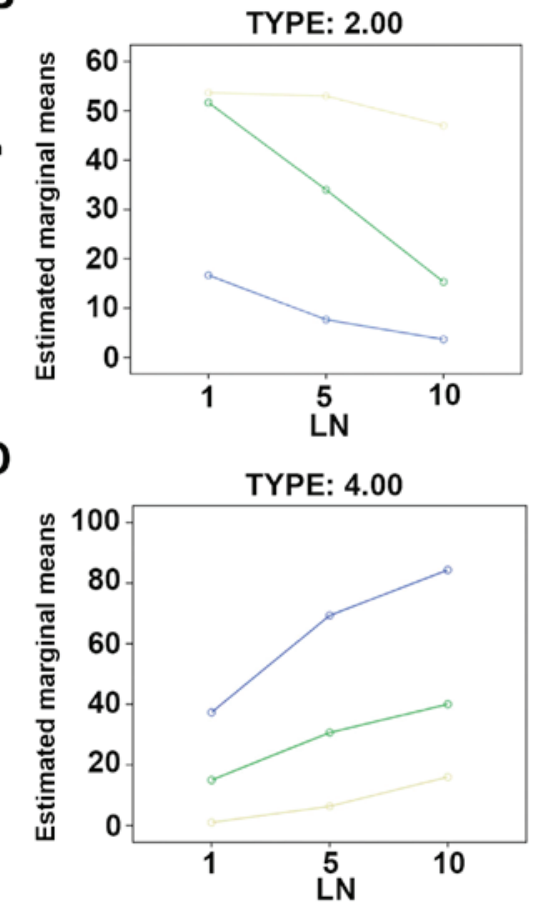

$\mathbf{F}$

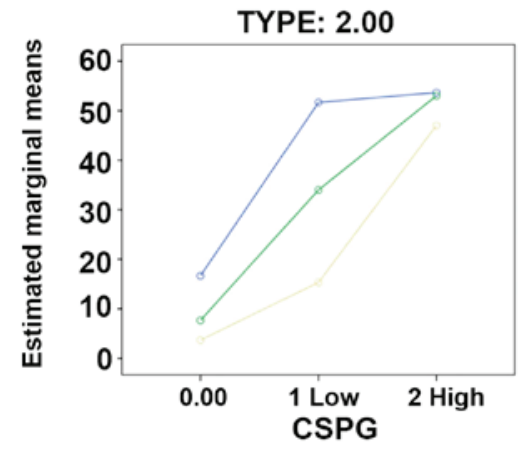

H

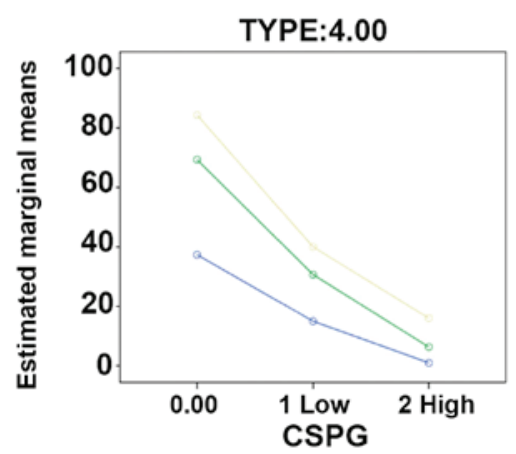

Figure 10. Interactive effect of laminin and CSPGs on the differentiation of OPCs. The distribution of type (A) I, (B) II, (C) III and (D) IV oligodendrocytes was changed after treatment with different concentrations of laminin and a specified concentration of CSPGs. The distribution of type (E) I, (F) II, (G) III and (H) IV oligodendrocytes was changed after treatment with different concentrations of CSPGs and a specified concentration of laminin. Low CSPGs, $2.5 \mu \mathrm{g} / \mathrm{ml}$; high CSPGs, $5 \mu \mathrm{g} / \mathrm{ml}$. CSPG, chondroitin sulfate proteoglycan; OPC, oligodendrocyte precursor cell.

of the present study, as an alteration in $\beta 1$-integrin protein and mRNA expression levels were observed in CSPG-treated OPCs.

CSPGs are an important component of the ECM, which have been previously reported to regulate the differentiation and migration of multipotent neural precursor cells through the integrin signaling pathway (23). The results of the present study indicate that CSPGs also regulate similar events in OPCs. CSPGs inhibited the differentiation of OPCs, including the outgrowth of processes in oligodendrocytes. However, the expression of $\mathrm{O} 1$ and MBP in CSPG-treated cells was still observed. This revealed that the inhibitory effect of CSPGs on oligodendrocyte maturation was not due to their suspension at a precursor stage, but the inhibition of the processes extension. 
Table II. Distribution of the different subtypes of oligodendrocytes.

\begin{tabular}{|c|c|c|c|c|c|}
\hline Subtype of oligodendrocyte & Source & Sum of squares (type III) & Mean square & F-value & P-value \\
\hline \multirow[t]{3}{*}{ I } & $\mathrm{LN}$ & 786.074 & 393.037 & 82.264 & $<0.0001$ \\
\hline & CSPGs & $1,643.185$ & 821.593 & 171.96 & $<0.0001$ \\
\hline & CSPGs*LN & 951.259 & 237.815 & 49.775 & $<0.0001$ \\
\hline \multirow[t]{3}{*}{ II } & $\mathrm{LN}$ & $1,568.296$ & 784.148 & 81.119 & $<0.0001$ \\
\hline & CSPGs & $7,964.963$ & $3,982.481$ & 411.98 & $<0.0001$ \\
\hline & CSPGs*LN & 759.259 & 189.815 & 19.636 & $<0.0001$ \\
\hline \multirow[t]{3}{*}{ III } & $\mathrm{LN}$ & 57.407 & 28.704 & 3.708 & 0.0450 \\
\hline & CSPGs & 568.074 & 284.037 & 36.694 & $<0.0001$ \\
\hline & CSPGs*LN & $2,126.593$ & 531.648 & 68.682 & $<0.0001$ \\
\hline \multirow[t]{3}{*}{ IV } & $\mathrm{LN}$ & $3,844.667$ & $1,922.333$ & 186.70 & $<0.0001$ \\
\hline & CSPGs & $14,364.222$ & $7,182.111$ & 697.54 & $<0.0001$ \\
\hline & CSPGs*LN & 917.778 & 229.444 & 22.284 & $<0.0001$ \\
\hline
\end{tabular}

LN, laminin; CSPGs, chondroitin sulfate proteoglycan; CSPGs*L, chondroitin sulfate proteoglycan and laminin.
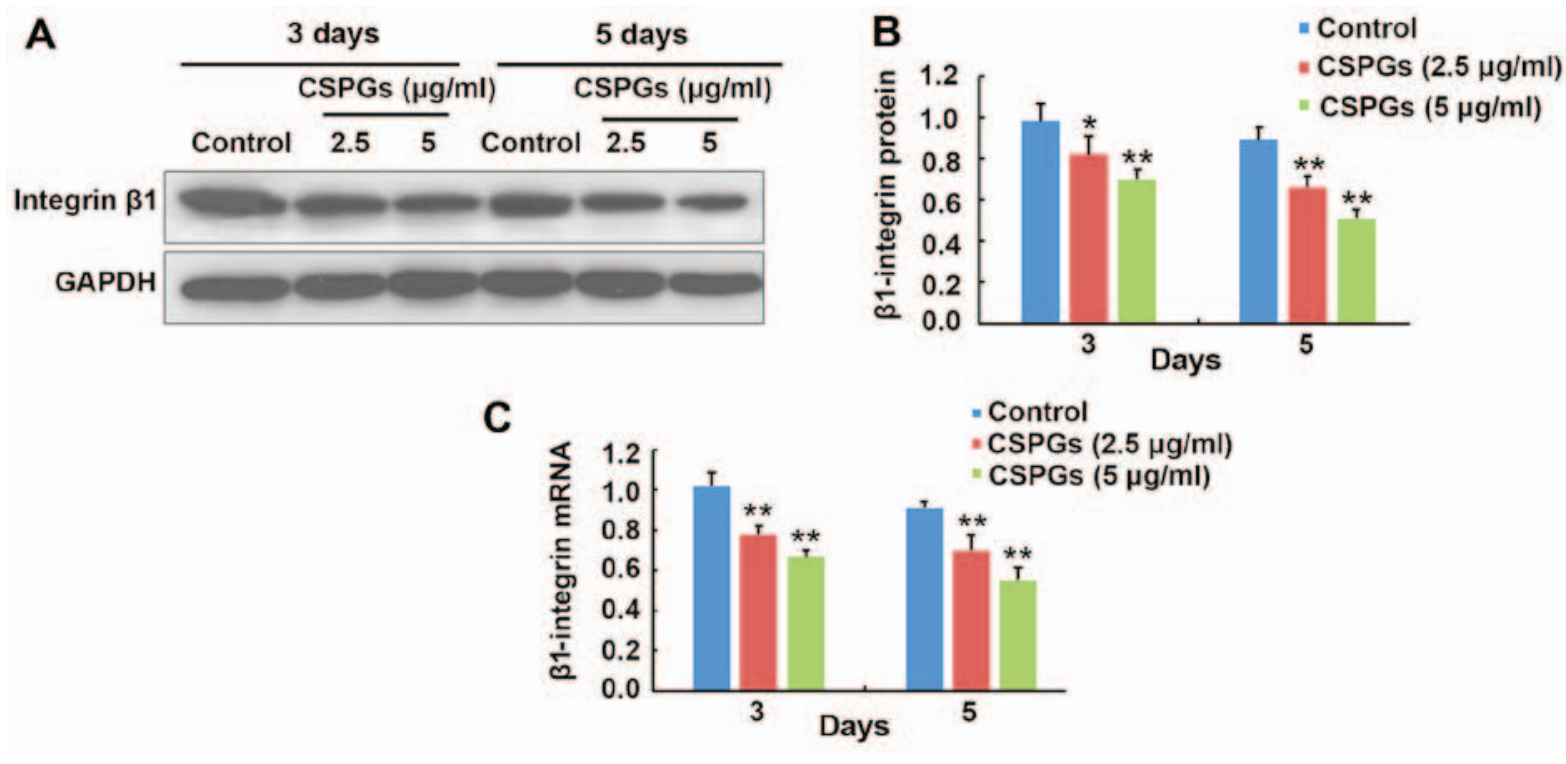

Figure 11. CSPG-induced inhibition of OPC maturation is associated with $\beta 1$-integrin. (A) Western blotting and (B) western blot quantification revealed that the protein level of $\beta 1$-integrin was significantly decreased in CSPG-treated OPCs compared with the control at 3 and 5 days following treatment. (C) The mRNA expression level of $\beta 1$-integrin was also significantly reduced compared with the control in CSPG-treated OPCs after 3 and 5 days. ${ }^{*}<0.05$ and ${ }^{* * *} \mathrm{P}<0.01$ vs. the control group. CSPG, chondroitin sulfate proteoglycan; OPC, oligodendrocyte precursor cell.

Following treatment with CSPGs it was observed that the OPCs were more detached and had fewer processes. This meant that CSPGs only inhibited the process of extension, but did not cause the death of OPCs. Further investigation is required to determine whether detachment is due to the impaired capacity for process outgrowth or the competition between laminin and adhesion molecules. Furthermore, detachment occurred when bFGF and PDGF-AA were replaced by T3 and T4. Therefore, it was hypothesized that these growth factors may protect OPCs from CSPGs treatment.

$\mathrm{Yu}$ et al (24) identified that laminin was required for morphogenesis in the radial axonal sorting of Schwann cells, mediated by the ErbB-cdc42 and $\beta 1$-integrin-Rac1 signaling pathways. As Racl is the downstream factor of $\beta 1$-integrin, laminin may regulate this process in Schwann cells through the $\beta 1$-integrin-Rac1 signaling pathway. A similar situation may occur in OPCs based on the previous finding that laminin regulates oligodendrocyte production in the subventricular zone (25). Further studies investigating the underlying mechanism of this are required to progress understanding of the role of CSPGs in OPC migration and differentiation, and the possibility for a novel therapeutic target for the treatment of WMI in premature infants.

\section{Acknowledgements}

The present study was supported by the National Natural Science Foundation of China (grant no. 81070520). 


\section{References}

1. SanGiovanni JP, Allred EN, Mayer DL, Stewart JE, Herrera MG and Leviton A: Reduced visual resolution acuity and cerebral white matter damage in very-low-birthweight infants. Dev Med Child Neurol 42: 809-815, 2000.

2. Muglia LJ and Katz M: The enigma of spontaneous preterm birth. N Engl J Med 362: 529-535, 2010.

3. du Plessis AJ: Neurology of the newborn infant. Preface. Clin Perinatol 36: xi-xiii, 2009.

4. Wilson-Costello D, Friedman H, Minich N, Fanaroff AA and Hack M: Improved survival rates with increased neurodevelopmental disability for extremely low birth weight infants in the 1990s. Pediatrics 115: 997-1003, 2005.

5. Groenendaal F, Termote JU, van der Heide-Jalving M, van Haastert IC and de Vries LS: Complications affecting preterm neonates from 1991 to 2006: What have we gained? Acta Paediatr 99: 354-358, 2010.

6. Msall ME: Central nervous system connectivity after extreme prematurity: Understanding autistic spectrum disorder. J Pediatr 156: 519-521, 2010.

7. Volpe JJ, Kinney HC, Jensen FE and Rosenberg PA: The developing oligodendrocyte: Key cellular target in brain injury in the premature infant. Int J Dev Neurosci 29: 423-440, 2011.

8. Back SA, Luo NL, Mallinson RA, O'Malley JP, Wallen LD, Frei B, Morrow JD, Petito CK, Roberts CT Jr, Murdoch GH, et al: Selective vulnerability of preterm white matter to oxidative damage defined by F2-isoprostanes. Ann Neurol 58: 108-120, 2005.

9. Khwaja $\mathrm{O}$ and Volpe JJ: Pathogenesis of cerebral white matter injury of prematurity. Arch Dis Child Fetal Neonatal Ed 93: F153-F161, 2008.

10. Billiards SS, Haynes RL, Folkerth RD, Borenstein NS, Trachtenberg FL, Rowitch DH, Ligon KL, Volpe JJ and Kinney HC: Myelin abnormalities without oligodendrocyte loss in periventricular leukomalacia. Brain Pathol 18: 153-163, 2008.

11. Back SA, Luo NL, Borenstein NS, Levine JM, Volpe JJ and Kinney HC: Late oligodendrocyte progenitors coincide with the developmental window of vulnerability for human perinatal white matter injury. J Neurosci 21: 1302-1312, 2001.

12. Galtrey CM and Fawcett JW: The role of chondroitin sulfate proteoglycans in regeneration and plasticity in the central nervous system. Brain Res Brain Res Rev 54: 1-18, 2007.

13. Carulli D, Laabs T, Geller HM and Fawcett JW: Chondroitin sulfate proteoglycans in neural development and regeneration. Curr Opin Neurobiol 15: 116-120, 2005.
14. Siebert JR and Osterhout DJ: The inhibitory effects of chondroitin sulfate proteoglycans on oligodendrocytes. J Neurochem 119: 176-188, 2011.

15. O'Meara RW, Ryan SD, Colognato H and Kothary R: Derivation of enriched oligodendrocyte cultures and oligodendrocyte/neuron myelinating co-cultures from post-natal murine tissues. J Vis Exp 54: 3324, 2011.

16. Livak KJ and Schmittgen TD: Analysis of relative gene expression data using real-time quantitative PCR and the 2(-Delta Delta C(T)) method. Methods 25: 402-408, 2001.

17. Back SA and Rosenberg PA: Pathophysiology of glia in perinatal white matter injury. Glia 62: 1790-1815, 2014.

18. Volpe JJ, Kinney HC, Jensen FE and Rosenberg PA: Reprint of 'The developing oligodendrocyte: Key cellular target in brain injury in the premature infant'. Int J Dev Neurosci 29: 565-582, 2011.

19. Sirko S, von Holst A, Wizenmann A, Götz M and Faissner A: Chondroitin sulfate glycosaminoglycans control proliferation, radial glia cell differentiation and neurogenesis in neural stem/progenitor cells. Development 134: 2727-2738, 2007.

20. O'Meara RW, Michalski JP and Kothary R: Integrin signaling in oligodendrocytes and its importance in CNS myelination. J Signal Transduct 2011: 354091, 2011.

21. Buttery PC and ffrench-Constant C: Laminin-2/integrin interactions enhance myelin membrane formation by oligodendrocytes. Mol Cell Neurosci 14: 199-212, 1999.

22. Olsen IM and Ffrench-Constant C: Dynamic regulation of integrin activation by intracellular and extracellular signals controls oligodendrocyte morphology. BMC Biol 3: 25, 2005.

23. Gu WL, Fu SL, Wang YX, Li Y, Lü HZ, Xu XM and Lu PH: Chondroitin sulfate proteoglycans regulate the growth, differentiation and migration of multipotent neural precursor cells through the integrin signaling pathway. BMC Neurosci 10: 128 , 2009.

24. Yu WM, Chen ZL, North AJ and Strickland S: Laminin is required for Schwann cell morphogenesis. J Cell Sci 122: 929-936, 2009.

25. Relucio J, Menezes MJ, Miyagoe-Suzuki Y, Takeda S and Colognato H: Laminin regulates postnatal oligodendrocyte production by promoting oligodendrocyte progenitor survival in the subventricular zone. Glia 60: 1451-1467, 2012. 